\title{
Revisiting the Buffering Hypothesis: Social Support, Work Stressors, Stress Related Symptoms, and Negative Affectivity in a Sample of Public School Teachers
}

\author{
Brian Heshizer1, Debra Erdos Knapp² \\ ${ }^{1}$ School of Business, Georgia Southwestern State University, Americus, GA, USA \\ ${ }^{2}$ School of Business Administration, Kent State University, Kent, OH, USA \\ Email: Brian.heshizer@gsw.edu
}

How to cite this paper: Heshizer, B. and Knapp, D.E. (2016) Revisiting the Buffering Hypothesis: Social Support, Work Stressors, Stress Related Symptoms, and Negative Affectivity in a Sample of Public School Teachers. Open Access Library Journal, 3: e3057.

http://dx.doi.org/10.4236/oalib.1103057

Received: September 13, 2016

Accepted: October 9, 2016

Published: October 12, 2016

Copyright $\odot 2016$ by authors and Open Access Library Inc.

This work is licensed under the Creative Commons Attribution International

License (CC BY 4.0).

http://creativecommons.org/licenses/by/4.0/

\section{cc) (i) Open Access}

\section{Abstract}

This study tests if forms of social support have a buffering effect on the relationship between actual workplace risk job stress and psychosomatic work stress taking into account Negative Affectivity (NA). The buffering effect maintains that social support acts a moderator variable that enables individuals to withstand the adverse impact of work stress on psychological states such as psychosomatic stress and job stress. Additionally, as suggested in the job stress literature, a measure that assesses an individual's predisposition to be effected by the presence of work stressors, negative affectivity, which is a personality variable that involves the experience of negative emotions and poor self-concept, is included. Low negative affectivity is characterized by frequent states of calmness and confidence while high negative affectivity with unease and lack of confidence. Negative affectivity may influence the degree to which stressful events affect the level of stress experienced by individuals. Thus previous studies that report a relationship between work stressors and work related stress symptoms may overstate the actual impact that stressors have because negative affectivity has not been incorporated as a control variable. This study will also examine whether social support continues to buffer the relationship between stressors and stress symptoms when NA is included in the model. Based on the relevant literature, hypotheses are stated on the effect that NA has on the stressor-stress symptom relationship and if social support buffers (moderates) the relationship between stressors with NA as a model variable. These hypotheses are tested with a sample of urban, public school teachers from a large metropolitan school district. Implications of study outcomes and suggestions for future research are discussed. 


\section{Subject Areas}

Psychology

\section{Keywords}

Workplace Stress, Negative Affectivity, Stress Symptoms, Social Support, Buffering Hypothesis

\section{Introduction}

The buffering effect of social support remains a stress research topic that is still not settled. Given the fact that work stress is widespread and has serious job, health, and personal consequences, research continues on role of social support as a mechanism that buffers the negative effects of work stress [1]-[8]. One issue that has been put forth is that personal dispositions that make individuals more vulnerable to stressors need to be incorporated into research on job stress since such variables may influence the job stressor-stress symptom relationship [9]-[12]. Researchers have argued that negative affectivity (NA), a personal disposition associated with the emotions of fear and nervousness, can significantly impact the relationship between stressors, social support, and work related stress symptoms [1] [12] [13]. The reason to include NA is that it may underlie respondents' reports of stressors and stress-related symptoms, and that failure to incorporate NA may lead researchers to conclude that stressors alone predict the level of stress related outcomes. In response to this suggestion, we include NA in this study which we believe that will provide a more accurate assessment of the relationship between stressors and stress related outcomes [6] [14]-[16]. In regards to the buffering hypothesis, the question is whether social support will still act as moderator when the model includes NA. To our knowledge there has been no previous research that has assessed the buffering effect with NA as a model variable. In the rest of this section, we will discuss the variables included in our research model to lay the foundation for the research hypotheses that we shall propose.

Many studies have identified work stress as a factor that can decrease job performance, lead to as job dissatisfaction, and contribute to the development of adverse psychological conditions [3] [17]-[19]. Sources of workplace stress are numerous and can be affected by both job and situational factors. Consequently, a large body of research has examined such factors as role conflict, ambiguity, and work overload as antecedents of work related stress symptoms [3] [10] [15] [18] [20].

This study takes a different perspective on the source of work stressors by positing that work stress can also result from the presence of and the amount of risk posed by unpleasant and threatening events which occur in the workplace [13]. Several studies have used the presence of actual danger or threats in the workplace and the risk posed by these dangers was assessed as a source of workplace stress [11] [13] [21]. Referred to as actual danger, this work stressor recognizes that jobs can vary in terms of the num- 
ber of stressful events that are likely to occur and that an employee's assessment of the presence, frequency, and intensity of stressful work events is an important work stressor [13]. It is this work stressor that is used in this study.

Another area of interest in stress research has been role of social support as a condition that mitigates the impact of work stressors on stress outcomes. Social support is defined as resources, including material aid, socio emotional support, and informational aid, provided by others to help a person cope with stress [2] [8] [22]. In general, a lack of social support relationships can lead to negative psychological states such as anxiety and depression [6] [8] [17] [22] [23]. One research stream argues that social support has a direct (or main) effect on stress reactions. According to the main effect school, social support directly helps individuals deal with the amount and intensity of stress-related symptoms, irrespective of the degree of risk and danger to which individuals are exposed [1] [4]. Proponents of the main effect school maintain that individuals benefit overall from social networks because they provide regular positive experiences and provide individuals with information and experience that enables them to avoid and deal more effectively with work stressors.

Another school of thought argues that social support buffers or moderates the relationship between stressors and stress symptoms [1] [4] [6] [20] [22] [24]. The buffering hypothesis proposes that social support interacts with stressful events, thereby reducing the attitudinal and behavioral stress-related symptoms that may result. If social support moderates the relationship between stressful events and the occurrence of adverse psychological reactions, its presence would diminish the intensity of stress reactions and would partially alleviate the impact of stressful events by enhancing one's ability to cope with stressors.

This study includes several forms of social support to determine their relationship to work stressors and work stress-related effects. It would be expected that social support mechanisms found within work environments (support from the organization and supervisors) would more likely have a stronger effect on lessening the impact of work stressors on workplace stress symptoms. On the other hand, social support networks more distant from the sources of stress (support from family) would tend to have a less ameliorative effect on workplace stress-related outcomes [1] [4]. In unionized workplaces, social support is often provided through the union [25]. For example, grievance procedures and contract provisions often include information and processes that specifically address work-related issues. In addition, unions provide the information, means, and social networks that have the potential to mitigate the negative outcomes associated with job-related stressors. Thus, unions provide another means of social support.

Unique to our study is the incorporation of NA into the stressor-stress outcome model. Individuals with high NA compared to those with low NA would tend to react more intensely to stressful events and are more likely to have higher levels of job stress and negative shifts in their affective moods. Hence, failing to consider negative affectivity can lead to the spurious conclusion that a relationship exists between stressors and stress-related symptoms when in fact it is the presence of negative affectivity that in- 
fluences the reaction of individuals to stressors and their stress symptoms. In regard to the buffering hypothesis it is unclear as to the effect that NA will have. It is quite possible that the buffering effect will still be present if NA does not significantly covary with the interaction term, social support and actual danger. At this juncture we do not identify a specific hypothesis on NA's effect on the buffering role of social support.

To sum up, the model of occupational stress followed here conceptualizes stress as unpleasant emotional experience resulting from events in the work environment that involves danger, anxiety, irritation, or anger. The model maintains that stressful events consist of subjective perceptions of and the actual occurrence of stressors and of the intensity or risk associated with these stressors. The combination of work stressors and the perceived intensity associated with the work stressor can lead to increased job stress and psychosomatic conditions. Social support is presumed to assist in alleviating the impact of stressful events on these symptoms as a main effect or as a moderator. Negative affectivity is included in the model to control for the confounding effect that negative mood states can have on individual perceptions of stressors and stress-related symptoms and on the buffering effect of social support.

\section{Hypotheses}

Given the expected role that NA has as a disposition that predisposes individuals to be more sensitive to work stressors, we propose the following hypothesis.

Hypothesis 1: Negative affectivity is predicted to be positively related to workplace stress outcomes. Individuals with higher levels of NA are more likely to experience stress-induced job stress and psychological states than those individuals that have low negative affectivity.

The next two hypotheses address the issue of social support as a buffer or moderator between work stressors and stress-related symptoms versus social support as a main effect. If social support has a main effect, we would expect social support to have the same impact regardless of the level of support. Alternatively, if the results indicate that social support moderates the relationship between stressors and stress-related symptoms (i.e., the buffering effect), then the interaction of social support and work stressors should be significant and have the effect of reducing the level of job and psychological stress reported by subjects.

Hypothesis 2: If the social support variable-work stressor interaction variable is significant, social support moderates the relationship between work stressors and stressrelated outcomes (the buffering effect).

Hypothesis 3: If the social support variable-work stressor interaction term is insignificant, social support has a main effect on job stress.

\section{Method}

\subsection{Sample}

There has been a large volume of research dealing with teacher stress [3] [23] [24] [26]-[28]. Building on the opportunity to expand the research stream on teacher stress, 
we obtained the cooperation of a large mid-western school system to collect the data for our. The respondents for this study were 276 public school teachers from a large, Midwestern, unionized urban school system who responded to a mail questionnaire. One thousand questionnaires were sent to two subgroups of teachers in the system. Four hundred and twenty-five (425) surveys were sent to all teachers with three or fewer years of experience in the system. One hundred and forty-nine (149) usable surveys were returned, resulting in a response rate of approximately $35 \%$. The remaining surveys (575) were sent to a random sample of teachers with more than three years of tenure in the system. The number of usable surveys returned was 127, a response rate of $22 \%$. Of the total respondents, $45 \%$ percent taught in elementary school (grades $1-5$ ), $35 \%$ taught in middle school (grades $6-8$ ), and 20\% taught at the high school level (grades 9 - 12). Seventy-six percent $(76 \%)$ of respondents were female and $24 \%$ were male. The racial composition was $81.5 \%$ non-minority and $18.5 \%$ African American. The average age of respondents was 38.8 years, ranging from 22 to 62 years. Respondents in the group with more than three years of tenure had an average of 19.9 years of experience, while the group with less than three years of tenure averaged 1.96 years of teaching experience. The range for teaching experience was from less than one year up to 36 years. Concerning the variables of interest, the two groups differed significantly on psychosomatic job stress: more experienced teachers indicated much higher levels of job stress. Moreover, teachers with less than three years of experience reported higher levels of organizational support. Correlations between stress-related symptoms, subjective stress, actual danger, and negative affectivity were significant and in the expected directions. The means, standard deviations, reliability coefficients, and correlations are available from the first author upon request.

\subsection{Measures: Independent Variables}

Actual Danger. Actual danger was used as the measure of work stress. Actual danger was measured using the product of two responses to four questions from a Risk Assessment Survey [13]. First, on a three-point scale (never, 1 or 2 times, 3 or more times), respondents answered questions concerning whether or not a certain event had ever taken place, such as "Student has been verbally abusive" and "Student has struck you". Next, on a four-point Likert scale ranging from No Risk to Very Great Risk, respondents answered the degree of risk posed by said event. The scale was the sum of the products of these responses and had a reliability $(\alpha)$ of 0.88 .

Organizational Support. Organizational support was measured using the Organizational Support Survey developed by Eisenberger, Huntington, Hutchison, and Sowa [2]. Using a five-point Likert scale ranging from Strongly Disagree to Strongly Agree, respondents answered six questions such as: "The school system would ignore any complaint from $m e$ " and "The school system cares about my well being". Organizational support was the sum of the responses to the six questions ( $\alpha=0.89$ ).

Union Support. Union support was measured using the Perceived Union Support Survey developed by Shore, Tetrick, Sinclair, and Newton [25]. Using a five-point Li- 
kert scale ranging from Strongly Disagree to Strongly Agree, respondents answered the extent to which they agreed or disagreed with five statements such as: "Help is available from the Teacher's Union when I have a problem". Union support was the sum of the responses to the five questions $(\alpha=0.92)$.

Social Support from: the Principal, Fellow Teachers, and Family. These three variables were taken from the Social Support Survey developed by Sarason, Levin, Basham, \& Sarason [5]. Each consisted of four items on a four-point Likert scale ranging from Not at all to Very Much, asking for responses to questions such as: "How much do principall fellow teachers/ family go out of their way to do things to make your work life easier?" The sum of the three responses for each was used to determine the level of social support from principals and coworkers. The reliability $(\alpha)$ coefficients were: Support from principals $=0.89$, from fellow teachers $=0.88$, and from family $=0.83$.

Negative Affectivity. This variable was measured with an 18 -item dichotomous scale adapted from Taylor [9]. The items required a Yes or No response to statements such as "I am as nervous as other people" and "I feel anxious about things almost all the time". The scale had a reliability coefficient of 0.82 (Kuder-Richardson).

\subsection{Measures: Dependent Variables}

Job Stress. Job stress was measured using the Job Stress Survey developed by Steffy and Jones [20]. Using a five-point Likert scale, respondents answered the degree to which they agreed or disagreed with ten statements such as: "I experience too much pressure on my job" and "Sometimes I feel I can't take it anymore". Job stress scores were calculated by summing the items and had a reliability coefficient (Cronbach's $\alpha$ ) of 0.92 .

Psychosomatic Job Stress. The measurement for this variable was adapted from Steffy and Jones and consisted of a seven-item Likert scale ranging from Strongly Disagree to Strongly Agree [20]. Respondents answered statements such as: "Do you feel nervous on the job?" and "Do you feel fatigued on the job?" Again, psychosomatic job stress was obtained by summing the scale items and had a reliability coefficient (Cronbach's $\alpha$ ) of 0.84 .

\section{Results}

Regression analysis was used to test the proposed relationships. In all regression models, gender, age, and tenure were entered in the first step as control variables. Negative Affectivity (NA) was then entered to test whether dispositional affect underlies the relationship between stressful events and symptoms. To test the buffering hypotheses, a moderated regression analysis following the method advocated by Stone and Hollenbeck was used to determine whether social support has a main effect or moderating (i.e., buffering) effect [29]. An interaction variable calculated as the product of social support and actual danger was introduced into the regression model. If the interaction term is significant, social support moderates the relationship between actual danger and the stress outcomes, either job stress or psychosomatic job stress. If the interaction term is not significant but social support is significant, a main effect is present. The regres- 
sion results are shown in Table 1.

Hypothesis 1 predicted that negative affectivity will have a positive impact on stress-related symptoms (i.e., increases in the level of NA increases increase the level of job stress and psychosomatic job stress). The regression results in Table 1 support the hypothesis: NA had a statistically significant, positive impact on each stress-related symptom in all regression models.

Hypotheses 2 and 3 address whether social support has a moderator or main effect. Hypothesis 2 states that social support will moderate the relationship between actual danger and job stress symptoms which would be supported if the social support-actual danger interaction term is significant. The regression results however do not show any moderator effects. In each model the social support and actual work danger interaction

Table 1. Moderator effects of organizational and social support on job stress and psychosomatic job stress ${ }^{\mathrm{a}}$.

\begin{tabular}{|c|c|c|c|c|}
\hline & \multicolumn{4}{|c|}{ Psychosomatic } \\
\hline & \multicolumn{2}{|c|}{ Job Stress } & \multicolumn{2}{|c|}{ Job Stress } \\
\hline & $\beta$ & $\Delta \mathrm{R}^{2}$ & $\beta$ & $\Delta \mathrm{R}^{2}$ \\
\hline 1. Negative Affectivity (NA) & $0.44^{* * *}$ & 0.24 & $0.42^{* * *}$ & $0.21^{* * *}$ \\
\hline 2. Organization Support (OS) & $-0.25^{\star * *}$ & & $-0.18^{\star}$ & \\
\hline Actual Danger (AD) & $0.10^{* * *}$ & 0.07 & 0.16 & $0.08^{* * *}$ \\
\hline 3. $\mathrm{OS} \times \mathrm{AD}$ & 0.01 & 0.18 & 0.08 & 0.01 \\
\hline 1. NA & $0.44^{* * *}$ & 0.24 & $0.42^{* * *}$ & $0.21^{* * *}$ \\
\hline 2. Union Support (US) & -0.04 & & & -0.11 \\
\hline $\mathrm{AD}$ & $0.46^{*}$ & $0.08^{\star * *}$ & 0.18 & $0.07^{* * *}$ \\
\hline 3. $\mathrm{US} \times \mathrm{AD}$ & 0.20 & 0.01 & 0.08 & 0.01 \\
\hline 1. NA & $0.44^{* * *}$ & 0.24 & $0.42^{* * *}$ & $0.21^{* * *}$ \\
\hline 2. Principal Support (PS) & $-0.33^{* * *}$ & & $-0.21^{\star *}$ & \\
\hline $\mathrm{AD}$ & 0.05 & $0.13^{* * *}$ & 0.18 & $0.09^{* * *}$ \\
\hline 3. $\mathrm{PS} \times \mathrm{AD}$ & 0.23 & 0.01 & 0.08 & 0.01 \\
\hline 1. NA & $0.44^{\star * *}$ & 0.24 & $0.42^{\star *}$ & $0.21^{\star *}$ \\
\hline 2. Family Support (FS) & -0.03 & & -0.02 & \\
\hline $\mathrm{AD}$ & 0.33 & $0.07^{\star * \star}$ & 0.23 & $0.06^{* * *}$ \\
\hline 3. $\mathrm{FS} \times \mathrm{AD}$ & -0.07 & 0.01 & 0.04 & 0.01 \\
\hline 1. NA & $0.44^{\star * *}$ & 0.24 & $0.42^{\star * *}$ & $0.21^{* * *}$ \\
\hline 2. Teacher Support (TS) & -0.06 & & $-0.16^{* *}$ & \\
\hline $\mathrm{AD}$ & $0.40^{*}$ & $0.08^{* * *}$ & 0.07 & $0.07^{* * *}$ \\
\hline 3. $\mathrm{TS} \times \mathrm{AD}$ & -0.14 & 0.01 & 0.19 & 0.01 \\
\hline
\end{tabular}

${ }^{\mathrm{a}}$ Gender, Race, and Tenure were included as control variables in each model. The $\Delta \mathrm{R}^{2}$ was $0.05, \mathrm{p}<0.01$ in the Job Stress equation; 0.10, $\mathrm{p}<0.0001$ in the Psychosomatic Affect equation. ${ }^{\star} \mathrm{p}<0.05 ;{ }^{* *} \mathrm{p}<0.01 ;{ }^{* * *} \mathrm{p}<0.001$. 
term was not significant. Hypothesis 3 states that social support has a main effect which would be identified where the social support variable is significant. The regressions in Table 1 show that when job stress is the dependent variable, organizational support and support from the school principal showed main effects: these social support measures were significant and negative. Thus, higher levels of organizational support and support from the principal, reduced job stress. In the regressions with psychometric job stress as the dependent variable, organizational support, support from the principal, and support from fellow teachers had significant main effects: higher levels of these social support forms reduced psychosomatic stress. In sum, main effects predominated even controlling for negative affectivity. These results offer more support for the main effect model rather than the buffering effect regarding the relationship between social support and workplace stress reactions.

\section{Discussion}

This study addressed the role of social support as a moderator or as a main effect on the relationship between self-reports of work stressors and stress-related symptoms, controlling for negative affectivity. Regarding NA, the results support the recommendation of that job stress research should include NA as a relevant factor [10] [12] [14] [16] [17]. Researchers have argued that the stressor-stress symptom relationship may be overstated and even spurious if NA is not included in the analysis. If NA is a factor that depresses the relationship between stressors and stress-related symptoms, significant relationships between job stressors and stress outcomes may not be found [6] [14] [15]. The regression analyses here showed that NA has a significant, negative effect on both job stress and psychosomatic stress but there still remained a significant relationship between actual danger, our work stressor measure, and the job stress and psychosomatic job stress. The argument that NA would suppress work the stressor-work stress outcome relationship was not found in our study. However, it still might be that NA partially suppresses the work stressor-work stress outcome relationship. We also note that NA had a much stronger correlation with job stress $(\mathrm{r}=0.51)$ and psychosomatic job stress $(0.49)$ than actual danger $(r=0.19)$. The need to include NA in work stress models is warranted and the role of NA on the stressor-stress outcome relationship needs further study.

The second issue in the study dealt with the question whether social support has a moderator or main effect on the stressor-stress outcome relationship. This study showed that social support predominated as a main effect. We found that support from the organization, principal, and fellow teachers acted positively in alleviating work related stress symptoms. These forms of support may provide workers with more instrumental or direct assistance in dealing with matters that originate in the work environment. Given our measure of work stress, the presence of actual danger (an objective stressor measure), it does appear that these forms of support operate directly on stress-related symptoms. Interestingly, union support did not have a significant impact as a form of social support for alleviating work stress. Perhaps teachers perceived the 
union's role as being carried out through fellow teachers rather than the by the union itself. Another possibility is that teachers viewed the union's role as the collective bargaining agent rather than as a means to address work stress.

\section{Implications}

This research also has some practical implications for public school organizations. Since stress outcomes can affect teacher performance, overall organizational effectiveness, and the ability to retain qualified professionals, school systems should consider social support mechanisms as a possible bulwark against these stress-linked problems. In particular, the social support role of principals and fellow teachers needs to be recognized and encouraged. Programs that formalize such forms of support (in addition to existing informal helping networks) may enhance their beneficial impact.

\section{Future Research}

Several areas of further research are suggested by this study include. First, the role of $\mathrm{NA}$ as a mediating variable in the stressor-stress outcome relationship deserves analysis. A mediating model could determine if stressors directly affect stress outcomes and are mediated through negative affectivity also [29] [30]. Second, NA may also influence the effectiveness that social support has as a mechanism to alleviate or aid workers in dealing with work stress symptoms. It is possible that NA moderates the relationship between social support and work stress symptoms, an issue deserving further study. Third, identifying a structural equation model that incorporates NA, social support, work stressors, and work stress symptoms may provide more insight into the relationship among these constructs.

Regarding social support, a determination as to how social support functions as a stress alleviating mechanism requires investigation. Does social support that provides social companionship, information, or instrumental support have a greater impact on stress-related symptoms? Does the adequacy of social support as opposed to its availability offer a better understanding of how social support operates? Finally, the impact of disposition cannot be ignored in work stress research. Research using other relevant measures of individual differences such as psychological hardiness, locus of control and self-esteem need to be undertaken to further our understanding of their influence on stressful events and stress-related symptoms.

\section{Conclusion}

Though work stress has been a subject of much research and study for over fifty years, we are still left with some important questions regarding the underlying psychological process involved. Our study does point to the need to include dispositional measures such as negative affectivity in work stressor-stress outcome research. While it is clear the NA does affect the stressor-stress outcome relationship, the nature of its effect needs further theoretical development and empirical study. Obviously there is more 
that should be done to integrate dispositions such as NA in the field of stress research. Hopefully, future work will appear that clarifies the role of such constructs in stress research.

\section{References}

[1] Cohen, S. and Wills, T.A. (1985) Stress, Social Support, and the Buffering Hypothesis. Psychological Bulletin, 98, 310-357. http://dx.doi.org/10.1037/0033-2909.98.2.310

[2] Eisenberger, R., Huntington, R., Hutchison, S., and Sowa, D. (1986) Perceived Organizational Support. Journal of Applied Psychology, 71, 500-507. http://dx.doi.org/10.1037/0021-9010.71.3.500

[3] Griffith, J., Steptoe, A. and Cropley, M. (1999) An Investigation of Coping Strategies with Job Stress in Teachers. British Journal of Educational Psychology, 696, 517-531. http://dx.doi.org/10.1348/000709999157879

[4] Pelfrene, E., Vlerick, P., Kittel, F., Mak, R., Kornitzer, M. and De Backer, G. (2002) Psychological Work Environment and Psychological Well-Being: Assessment of the Buffering Effects in the Job Demand-Control-Support Model. Stress and Health, 18, 43-56. http://dx.doi.org/10.1002/smi.920

[5] Sarason, I.G., Levine, H.M., Basham, R.B. and Sarason, B.R. (1983) Assessing Social Support: The Social Support Questionnaire. Journal of Personality \& Social Psychology, 44, 127-139. http://dx.doi.org/10.1037/0022-3514.44.1.127

[6] Sargent, L. and Terry, D. (2000) The Moderating Role of Social Support in Karasek's Job Strain Model. Work and Stress, 14, 245-261. http://dx.doi.org/10.1080/02678370010025568

[7] Vagg, P. and Spielberger, C. (1998) Occupational Stress: Measuring Job Pressure and Organizational Support in the Workplace. Journal of Occupational Psychology, 3, 294-305.

http://dx.doi.org/10.1037/1076-8998.3.4.294

[8] Wright, K.B., King, S. and Rosenberg, J. (2014) Functions of Social Support and Self-Verification in Association with Loneliness, Depression, and Stress. Journal of Health Communication: International Perspectives, 19, 82-99. http://dx.doi.org/10.1080/10810730.2013.798385

[9] Taylor, J. (1953) A Personality Scale of Manifest Anxiety. The Journal of Abnormal and Social Psychology, 48, 285-290. http://dx.doi.org/10.1037/h0056264

[10] Thorsteinsson, E.B., Rhonda, F.B. and Brown, F. (2014) The Relationship between WorkStress, Psychological Stress and Staff Health and Work Outcomes in Office Workers. Psychology, 5, 1301-1310. http://dx.doi.org/10.4236/psych.2014.510141

[11] Brief, A.P. and George, J.M. (1991) Psychological Stress and the Workplace: A Brief Comment on Lazuarus' Outlook. Journal of Social Behavior and Personality, 6, 15-20.

[12] Fullagar, C.J., Knight, P.A. and Sovern, H.S. (2013) Challenge/Skill Balance, Flow, and Performance Anxiety. Applied Psychology. An International Review, 62, 236-259. http://dx.doi.org/10.1111/j.1464-0597.2012.00494.x

[13] McLain, D.L. (1995) Reponses to Health and Safety Risk in the Work Environment. Academy of Management Journal, 38, 726-743. http://dx.doi.org/10.2307/256852

[14] Payne, R. and Morrison, D. (2002) The Differential Effects of Negative Affectivity on Measures of Well-Being Versus Job Satisfaction and Organizational Commitment. Anxiety, Stress, and Coping. An International Journal, 15, 231-244. http://dx.doi.org/10.1080/1061580021000020707

[15] Schaubroeck, J., Ganster, D. and Fox, M. (1992) Dispositional Affect and Work-Related 
Stress. Journal of Applied Psychology, 77, 322-335.

http://dx.doi.org/10.1037/0021-9010.77.3.322

[16] Jeronimus, B.F., Kotov, R., Riese, H. and Ormel, J. (2016) Neuroticism's Prospective Association with Mental Disorders Halves after Adjustment for Baseline Symptoms and Psychiatric History, But the Adjusted Association Hardly Decays with Time: A Meta-Analysis on 59 Longitudinal/Prospective Studies with 443,313 Participants. Psychological Medicine, 46, 1-24. http://dx.doi.org/10.1017/S0033291716001653

[17] Burke, R., Greenglass, E. and Schwarzer, R. (1996) Predicting Teacher Burnout over Time: Effects of Work Stress, Social Support, and Self-Doubts on Burnout and Its Consequences. Anxiety, Stress, and Coping: An International Journal, 9, 261-275. http://dx.doi.org/10.1080/10615809608249406

[18] Motowidio, S.J., Packard, J.-S. and Manning, M.R. (1986) Occupational Stress: Its Causes and Consequences for Job Performance. Journal of Applied Psychology, 71, 618-629.

http://dx.doi.org/10.1037/0021-9010.71.4.618

[19] Beehr, T.A. and Newman, J.E. (1978) Job Stress, Employee Health, and Organizational Effectiveness: A Facet Analysis, Model, and Literature Review. Personnel Psychology, 41, 665699. http://dx.doi.org/10.1111/j.1744-6570.1978.tb02118.x

[20] Steffy, B. and Jones, J.W. (1988) Workplace Stress and Indicators of Coronary-Disease Risk. Academy of Management Journal, 31, 686-698. http://dx.doi.org/10.2307/256466

[21] Kahneman, D. and Tversky, A. (1979) Prospect Theory: An Analysis of Decision under Risk. Econometrica, 47, 263-291. http://dx.doi.org/10.2307/1914185

[22] Rhoades, L. and Eisenberger, R. (2002) Perceived Organizational Support: A Review of the Literature. Journal of Applied Psychology, 87, 698-714.

http://dx.doi.org/10.1037/0021-9010.87.4.698

[23] Collie, R.J., Shapka, J.D. and Perry, N.E. (2012) School Climate and Social-Emotional Learning: Predicting Teacher Stress, Job Satisfaction, and Teaching Efficacy. Journal of Educational Psychology, 104, 1189-1204. http://dx.doi.org/10.1037/a0029356

[24] Kyriacou, C. (2001) Teacher Stress: Directions for Future Research. Educational Review, 53, 27-35. http://dx.doi.org/10.1080/00131910120033628

[25] Shore, L.M., Tetrick, L.E., Sinclair, R.R. and Newton, L.A. (1994) Validation of a Measure of Perceived Union Support. Journal of Applied Psychology, 79, 971-977. http://dx.doi.org/10.1037/0021-9010.79.6.971

[26] Pithers, R.T. (1965) Teacher Stress Research: Problems and Progress. British Journal of Educational Psychology, 65, 387-392. http://dx.doi.org/10.1111/j.2044-8279.1995.tb01160.x

[27] Yu, X., Wang, P., Zhai, X., Dai, H. and Yang, Q. (2015) The Effect of Work Stress on Job Burnout among Teachers: The Mediating Role of Self-Efficacy. Social Indicators Research, 122, 701-708. http://dx.doi.org/10.1007/s11205-014-0716-5

[28] Akpochafo, G.O. (2012) Perceived Sources of Occupational Stress among Primary School Teachers in Delta State of Nigeria. Education, 132, 826-833.

[29] Stone, E.F. and Hollenbeck, J.R. (1989) Clarifying Some Controversial Issues Surrounding Statistical Procedures for Detecting Moderator Variables: Empirical Evidence and Related Matters. Journal of Applied Psychology, 74, 3-10. http://dx.doi.org/10.1037/0021-9010.74.1.3

[30] Baron, R.M. and Kenny, D.A. (1986) The Moderator-Mediator Variable Distinction in Social Psychological Research-Conceptual, Strategic, and Statistical Considerations. Journal of Personality and Social Psychology, 51, 1173-1182.

http://dx.doi.org/10.1037/0022-3514.51.6.1173 
Submit or recommend next manuscript to OALib Journal and we will provide best service for you:

- Publication frequency: Monthly

- 9 subject areas of science, technology and medicine

- Fair and rigorous peer-review system

- Fast publication process

- Article promotion in various social networking sites (LinkedIn, Facebook, Twitter, etc.)

- Maximum dissemination of your research work

Submit Your Paper Online: Click Here to Submit

Or Contact service@oalib.com 